\title{
Pragmatist Aesthetics, Twenty Years Later
}

Understanding Interpretation, Interpreting Understanding

\section{Roberta Dreon}

\section{(2) OpenEdition}

Electronic version

URL: http://journals.openedition.org/ejpap/795

DOI: 10.4000/ejpap.795

ISSN: 2036-4091

\section{Publisher}

Associazione Pragma

Electronic reference

Roberta Dreon, « Pragmatist Aesthetics, Twenty Years Later », European Journal of Pragmatism and American Philosophy [Online], IV - 1 | 2012, Online since 23 July 2012, connection on 01 May 2019. URL : http://journals.openedition.org/ejpap/795 ; DOI : 10.4000/ejpap.795

This text was automatically generated on 1 May 2019.

\section{c) $(1)$}

Author retains copyright and grants the European Journal of Pragmatism and American Philosophy right of first publication with the work simultaneously licensed under a Creative Commons AttributionNonCommercial-NoDerivatives 4.0 International License. 


\title{
Pragmatist Aesthetics, Twenty Years Later
}

\author{
Understanding Interpretation, Interpreting Understanding
}

\section{Roberta Dreon}

1 Pragmatist Aesthetics was published in 1992, by now twenty years ago. Through his book Richard Shusterman was able to revitalize a debate in the aesthetic field, which tended to stagnate. But its claims, implications and consequences went beyond the narrow limits of aesthetics, understood as philosophy of art according to a traditional modern approach.

2 His reinterpretation of pragmatist aesthetics, expressly derived from Dewey's work, was able to show not only that those defining anxieties characterizing the analytical debate were not particularly successful, but also that the recent tendency to neglect aesthetic elements in favour of a complete translation in semantic terms of art's questions was not satisfactory. ${ }^{1}$

3 He recovered the basic pragmatist instance according to which aesthetic arguments, philosophical theses and, more generally, any intellectual elaboration must respond more or less indirectly to our everyday experiences, must explicitly pose the problem of improving our lives, of making them more meaningful and more satisfying for a wider number of people.

4 In comparison to continental approaches toward aesthetics, Pragmatist Aesthetics claimed the urgent need to risk a positive formulation of aesthetics. Those negative instances, as Adorno's ones, were able to resist a mere confirmation of existing institutions. Nevertheless they were characterised by a strong elitism, which tended to support social cleavages and to deny human structural needs of enjoying their own experiences.

5 Three basic guidelines therefore emerged from that book. The first one was to question the gap between authentic and popular arts, showing that we need no rigid dichotomy, which in its turn reveals itself as dogmatic and unfounded. Rather, we should discriminate within both artistic 'family groups' those relatives who are betters from the worse ones. More precisely, we should differentiate between regressive and fertile 
interaction modalities with works of art, between useless and enhancing artistic practices. His careful analysis of rap music (though probably not of the more recent commercial proposals) showed it can be very rich in terms of implications and references, and that it is characterised by an explicit awareness of its basic transformative and appropriative powers.

The second project concerned the opportunity to develop those forms of reception of the so called Fine Arts, which can be able to reinforce critical attitudes toward ethical and social conditions of existence - and in this sense Shusterman proposed a detailed analysis of Eliot's Portrait of a Lady, which insisted on its basic ambiguities.

7 Finally, a pragmatist aesthetics should recover the continuity of aesthetic aspects with ordinary life and put in question the habitual absence of aesthetic meanings from work, politics or science. Richard Shusterman insisted particularly on the necessity to restore the centrality of the body: despite its often neglected role in feeling, it is recognized as capable of peculiar forms of awareness, deeply relevant in our lives.

A current reader is also impressed by a basic pluralistic and anti-foundationalist attitude, we still need twenty years later. This kind of approach is proved in some pages problematizing the late romantic myth of artistic creation, and interpreting in a rather anti-dogmatic way the relations between common energies and ordinary materials, on the one hand, and individual instances, on the other one. This sincere non foundationalist attitude emerges also in the chapter devoted to interpretation, where Shusterman propose to think in circular terms the relations between more habitual and widely unreflective modes of understanding and more explicit and voluntary acts of interpretation, of critical stance - that is by denying the pervasiveness of interpretation when it is understood as the product of voluntary and primarily verbal acts.

It is this latter specific subject I propose to consider here, in order to confront its results with the recent philosophical debate. This is a topic that does not seem central among Richard Shusterman's latest interests. I suspect that he considers it as a rearguard matter and there are no doubt he prefers to explore without a safety net the new territories of a somaesthetics under construction. However I think it is still necessary to discuss these concepts that perhaps deserve a more explicit ontological stance, as I shall argue later, with respect to a certain return to realism in philosophy.

Besides it could also contribute to a more pluralistic view of the relations between linguistic and bodily aspects of our world experience, after the various turns that have played the leading role in the philosophical scene one after the other.

\section{Describing and Interpreting}

11 In his book two central chapters, "Pragmatism and Interpretation" and especially "Beneath Interpretation" - which do not appear in the Italian translation of Pragmatist Aesthetics - Shusterman advances the need to avoid monolithic solutions and to draw fine and elastic distinctions when speaking of interpretation. In general it emerges the thesis that supporting a strong form of contextualism about meanings, together with a resolutely anti-foundationalist and anti-representational approach in the epistemological field, does not imply falling into the simplistic formula according to which "there are no facts, only interpretations," that is to a radical constructivistic reading of Nietzsche's 
expression, whose ontological consequences would be the lost of the 'outside' world in favour of a certain range of subjective productions of our reality.

Richard Shusterman's greatest merit in this respect, as I mentioned before, is to dissolve the universal claims of interpretation in the interplay between forms of understanding and interpretive activities. Therefore I will consider here some significant steps of his reflexions. The chapter titled "Pragmatism and Interpretation" is dedicated to the issue of interpretation in literature, but it is quite clear that a certain conception of interpretation in this area is not considered as an independent one, on the contrary having broader implications - and we can remember that the continuity of eminently artistic practices with our daily interactions with our environment is one of the thesis opening Dewey's Art as Experience.

13 Is it possible to distinguish between description and interpretation when having to cope with a novel or a poem? Shusterman's answer is at first open, pragmatically possibilist: it depends on how we understand description. There are no difficulties if we do not think of it as a kind of picture just recording existing data, but as a particular collection of 'facts' on which a certain readers community agree in fairly stable circumstances, that is as selection of the most relevant aspects for interpretation. Moreover, such a distinction can be sustained if we do not mean the relationship between this kind of description and interpretation in foundational terms, because a new interpretation can react on the alleged initial data and revise them, correct them and eventually select other ones.

But Shusterman affirms that from a certain point of view just the removal of each descriptive layer in favour of a total interpreting, sustained by more radical deconstructionists, is connected to a reifying conception of meaning: if one assumes that there is something like an overt or a hidden meaning of the text, regardless of the readings that we can make of it, as Wolfgang Iser could say, interpretation becomes the only play in town, because in the absence of an already given meaning, we can attribute arbitrary meanings to the text. ${ }^{2}$ What you need doing is rather to stop thinking about meaning as a particular thing to decipher - the author's intention, the spirit of the time, an ideological message, a removed truth - and to understand interpretation differently. Interpreting a text is a kind of practice, is making something, giving it a meaningful answer in the sense that under certain conditions of experience - my reading, ours or that of someone other - it makes sense, it produces a certain experience of the world.

Clearly this is a "general hermeneutics direction," but it is not pervasive, because from the beginnings it is specified by two sets of considerations.

The first one concerns the fact that not all our answers to a text are guided by cognitive intents. For instance, we read for the pleasure we derive from a certain story, or because it is fertile for new imaginative possibilities. In other terms, the cognitive approach is not always the dominant one in reading: I do not read train timetables in order to know them, but to choose a train that takes me to my appointment at the appointed time. Furthermore, the response capable of making some literary work understandable is not necessarily a verbal one, but can be more direct and immediate. If the reading of the academic critic fits the idea of interpretation, our ordinarily reading can be adapted to the formula of "simply reading" or of understanding, while the idea that we are interpreting the text seems forced to us.

But while considering those aspects, Shusterman sketches a contextualist and antidogmatic background, where every single word has its own weight. 

the refusal of a reifying conception of meaning, are related to the rejection of a correspondentist version of truth. However the correspondence of our statements or our thoughts with independent objects 'in itself' or with alleged facts is unacceptable to the American pragmatist, not because the ones and the others are linguistically constructed, but because "independent objects [...] like facts, can not be isolated from our discoursive practices." The linguistic mediation is inevitable and makes unfeasible a world description from God's transcendental point of view, but that does not mean that it idealistically produces the world. In stark contrast with Rorty's familiar thesis according to which the liberating outcome of the linguistic turn would be the loss of the world, Shusterman noted in a footnote that this does not imply to reduce the world and its experience to language and a few pages later argues that to welcome the linguistic turn does not involve a similar reduction of the world and its experience to language. ${ }^{3}$ By making explicit an assumption not stated by the philosopher himself, I would simply say that in our experience we meet just the world and not our subjective projections, it is with our world that we are busy, not only thanks to a tangle of words, but also of habits, gestures, postures, feelings, practices, actions. It is this last point - that of noninterpretive and non-linguistic aspects of our experience - that takes Shusterman's attention. I understand his being ontological cautious in the name of a healthy pragmatic pluralism, but sometimes we need to make our ontological assumptions explicit.

If we can maintain the hermeneutical, understanding and interpretative character of our experiences, as I will explain later, it is because we think we are talking about it from the inside, and most of all to practice it from the inside. Therefore our postures, our gestures and our movements - from concrete to abstract and virtual ones - allow us to access our environment selectively and always in pre-oriented ways, but in fact it deals with an access to our shared world and not to our subjective constructions. In other words, it is our inherence to the world from its inside that produces the prospective character of our experience of things and ensures in the same time that it is our experience of things and not of mere mental projections.

\section{Preserving Immediate Understanding}

The heart of the matter for the American philosopher is to distinguish between understanding and interpretation in order to preserve the forms of immediate understanding. It seems to me that this is the underlying reason bringing him to criticize a pervasive notion of interpretation, while sharing an anti-foundationalist conception of human relationships with things - according to which our knowledge of what they are in themselves would ultimately be anchored in a perception of neutral data, that is of noninterpreted data, which would be given before additional meanings we could eventually attribute to them.

Shusterman begins his argument by claiming he shares the anti-foundationalist position supported by hermeneutic universalism, namely the rejection of the idea of a reality in itself, independently determined from the experience we have of it. Furthermore he explicitly recognizes that interpretation plays an important role in our experience of the world - indeed a irreplaceable one. However he says that "our intelligent and meaningful intercourse with the world includes non-interpretational experience, activity and understanding, so that we should not think that interpretation is the only game in town."

European Journal of Pragmatism and American Philosophy, IV - 1 | 2012 
${ }^{4}$ Therefore it appears to be more fertile to draw a functional distinction between interpretation and understanding, rather then a strictly ontological one, that is between interpreting and equally selective forms of experience, which are context specific and perspective, but not explicit, thoughtful or deliberate.

If it is wrong to believe that interpreting consists in discovering hidden layers of meaning, recognizing the structural perspective, partial, pre-oriented character of our experiences in the world does not imply that any form of understanding is interpretative. In everyday situations, but when we read a novel too, we implicitly orient ourselves according to our interests, prejudices, impulses, needs and habits, which, far from hindering our encounter with the world, allow us to understand it, as acknowledged by both supporters of hermeneutics and pragmatists. But it should be noted, against the alleged pervasiveness of interpretation, that very often our focus is implicit, unreflective, immediate. At least it functions this way all the times things work for themselves, when there is no problem, when, in Dewey's words, we are not faced with an indeterminate situation, where we do not know what to do, and we need to return analytically on various critical aspects to find a way-out, a solution. The role of interpretation is of this type. Clearly this is an absolutely central role in any critical situation, but not everywhere. Otherwise we would fall into the fallacy that all our intellectual selective behaviour should be guided by a clear thought and deliberate decisions. Instead, very often our behaviours are driven by habits, which are more or less intelligent but not conscious, so we know immediately what to do, how we have to relate to that individual in that situation, or to that text.

Shusterman's idea is therefore that interpretation is a behaviour, a type of reflective practice, knowingly and intentionally structured - a form of inquiry, to use Dewey's term. On the contrary understanding concerns the soil of our immediate experience, which are nevertheless mediated by words, habits, feelings, or more. But they are immediate in the sense that they pose no difficulties: individual and social habits, motor and conceptual patterns, intellectual and emotional biases work and we need not to put them in question. The point is not to assimilate all forms of active and selective intelligence to intellectual reflections, to differentiating and interpreting analysis, in order to preserve immediately significant environmental experiences.

The hermeneutical circle should be understood as a hermeneutic circularity of understanding and interpretation, characterized by complex stratification and mutual relations. The distinction between understanding and interpretation proposed by Shusterman is not strictly ontological, but based on their function, which in turn is not definitive, but open and, in certain situations, interchangeable. Generally, understanding works in the background, as basis and guide of interpretation, which, in its turn, explores, modifies, articulates its meaning. While understanding is unconscious, silent, because, proceeding from itself, it does not need to be said, to be noticed, interpretation requires an explicit stance, a conscious reflection aimed at resolving a crisis. Moreover, while when I am interpreting, I am usually aware of a plurality of possible alternatives, when I simply understand something without posing problems to myself, while being prospectively oriented, I am often blind to other alternatives. Finally, while interpretation is above all linguistically drawn, understanding is often not verbal but rather gestural, affective, habitual. It is not certain ineffable in the alleged mystical sense of the term: quite simply it often does not need to be said, does not require a speech because it simply works, and indeed there is no need to talk about it. But here it is, 
according to Shusterman's opinion, the critical point of hermeneutic universalism. It requires not only the thesis that all understanding is a form of interpretation but also the further one according to which every kind of understanding would be linguistic, since interpretation is eminently linguistic. If Gadamer argues that being that can be understood is language and, on the other side, Rorty and Derrida deny the existence of any "hors-texte," Shusterman warns us that the need for linguistic mediation does not exclude experiences that are meaningful without being linguistic, because they concern "those unmanageably illiterate and darkly somatic neighborhoods of town that we philosophers and literary theorists are occupationally accostomed to avoid and ignore, but on which we rely for our non-professional sustenance and satisfactions." ${ }^{5}$

\section{Something about Language}

It is a merit we can undoubtedly attribute to the American philosopher having recovered from pragmatist pluralism the need to recognize the richness of our experiences of the world, which are significant not only because of the language we speak, but also because of the way in which we move in it, of the orientation we assume, of the feelings we experience, of postural and behavioural habits we acquire, thoughts we largely implicitly adopt, bodily techniques and, I would add, extracorporeal technologies we commonly use. ${ }^{6}$ We do not always need say things, and nonetheless they are already significant for us.

The hermeneutical strategy of expanding the meaning of language, since to include nonverbal forms of experience, communication or signification, has been much discussed and it remains indeed questionable. If it can bring out the already significant and almost interlocutory structure of perception, of bodily movements, and of the various human practices, from an other point of view it risks to transform verbal language in a sort of transcendental condition of all forms of experience. But let me propose two sets of considerations in the spirit that characterizes Shusterman's frankly anti-dogmatic work.

The first one, whose the American philosopher is well conscious, but prefers leaving at the edge of his text, concerns the placement of language in the strict sense of the term with respect to the play between understanding and interpretation. It is clear that words constitute an outstanding way of analysis and reworking of the different elements of our experience and certainly more explicitly critical phases of our interactions with the world favour verbal language powerful determination and classificatory capacities. Therefore there is no doubt that interpretive practices do not require it as a tool simply intended as carrying out something already established by itself - of mental images or of state of things 'out there.' It is rather a powerful mean to actively intervene in the new elaboration of existential materials.

Shusterman rightly criticizes Davidson's thesis that all understanding of the interlocutor's speech would require a radical interpretation, because when we are moving ourselves in our mother tongue, and especially when words work and do not pose difficulties, understanding is largely habitual, implicit, immediate.

However, in these chapters the qualitative and almost bodily dimension of language remains largely neglected. I refer to those aspects of language such as, while we are reading a verse or a novel page, meaning is not only or not eminently given in referential forms, but it is based also on the sensual and affective texture of words, producing not primarily intellectual responses in the reader: pleasure, enjoyment, repulsion, attraction 
or an ambiguous mixture of both in front of obscenity or violence, for example. But this aesthetic dimension of language also affects our daily conversations, the components of timbre, melodic interjections, exclamations, pauses, or all those aspects that contribute to structure our relationships with others.

A second set of considerations concerns a certain primacy that seems to be attributed to an already fully significant but not linguistic bodily dimension. ${ }^{7}$ Of course when I feel pain - because of a wound or of a death - that is not a primarily linguistic experience, although it can be said in words, it may need it or not. However I am not entirely convinced we would feel pain - not physical and psychological, but somatic pain, in the anti-dualistic sense Shusterman rightly promoted - just as we human feel it, if we were not already immersed in a language before actually becoming able to speak and even before acquiring referentially oriented passive language skills.

This is not to support a new primacy of language, but to sustain - perhaps trivially - that interrelationships between linguistic and bodily aspects of our experience are always already behind us. We could talk about a form of mutual conditioning or of circularity between mostly bodily aspects and eminently linguistic ones, by which in the same time we feel and mean the world. Relations with it are played from the inside: they are therefore selective, prospective, already pre-oriented from our specific anchorage in it, but they are just about the world we belong to. They are not relations between a supposed inert subject and his private or shared hallucinations. On the other hand, if we want to talk about circularity, this is not analogous to the circle between understanding and interpretation, because there are no specific places or fixed means for the implicit, on the one hand, and for reflection, on the other.

As Shusterman taught us, there are forms of bodily awareness which are very attentive, and on the other side words may also have an immediate very strong emotional impact on us. To learn how to swim I have to be able to coordinate inhalation with the exit of my head from water and exhaling through the next dive, I have to pay attention to a breathing physiological habit as old as me, in order to change it in special circumstances. But the cry of a child who has finally learned to stay afloat, not to swallow water and then he does not even know how he moves his arms, unless you ask him, is completely natural and spontaneous, not mediated by reflection. On the other hand, to focus attention on the peculiar movement of the arm in freestyle, rather than in the frog, I learn to isolate on a both motor and linguistic level a certain analytic portion of an unitary practice. Then, when I learned well, I just enjoy the energetic pleasure of swimming - and calling it 'energetic' in retrospect I understand more clearly what I felt.

\section{NOTES}

1. Cfr. R. Shusterman, (1997), "The End of Aesthetic Experience," The Journal of Aesthetics and Art Criticism, (55) 1, 29-41.

2. Cfr. W. Iser, (1978), The Act of Reading: a Theory of Aesthetic Response, Baltimore, John Hopkins University Press. 
3. Cfr. R. Shusterman, (2000), Pragmatist Aesthetics. Living Beauty, Rethinking Art, Roman and Littlefield Publisher, Lanham, Boulder, New York, Oxford, 102; and 304, note 17.

4. R. Shusterman, Pragmatist Aesthetics, cit., 116-7.

5. R. Shusterman, Pragmatist Aesthetics, cit., 128.

6. Cfr. R. E. Innis, (2002), Pragmatism and the Forms of Sense. Language, Perception, Technics, University Park, Pennsylvania, The Pennsylavnia State University Press.

7. Cfr. M. Johnson, (2007), The Meaning of the Body. Aestetics of Human Understanding, Chicago and London, The University of Chicago Press.

\section{AUTHOR}

\section{ROBERTA DREON}

Università Ca' Foscari - Venezia

robdre[at]unive.it 